\title{
Implementation of Rapid Response Flow Reduces the Waiting Time of Patients with Chest Pain in an Emergency Unit
}

\author{
Marlon M Vilagra, Sandra Maria B Werneck, Bárbara Hang Loss, André Dias Lima Bonfim, Eduado \\ Jannuzi Cunha, Leandra Duarte Bastos, Lahís Werneck Vilagr, Henrik Werneck Vilagra, Marco Orsini* \\ and Eduardo Tavares Lima Trajano
}

Mestrado profissional em ciências aplicadas em saúde, Universidade Severino Sombra Vassouras RJ, Brazil

Received: April 21, 2018; Published: May 07, 2018

*Corresponding author: Marco Orsini, Mestrado profissional em ciências aplicadas em saúde, Universidade Severino Sombra Vassouras-RJ, Brazil

\section{Abstract}

Introduction: Chest pain (CP) is a frequent symptom in emergencies worldwide, presenting as a diagnostic challenge for the emergency room, due to the multiplicity of etiologies, and the diagnostic fluctuation between low and high-risk diseases. The optimized door-to-ECG time is a target and excellent index to be reached in the approach of the patient with TD. Rapid inflow to the hospital until the first EGG can be performed can accelerate the diagnosis and therapy in the patient with DT by determining a risk minimization.

Objective: To evaluate the impact of insertion of a rapid inflow of patients with chest pain in emergency on optimization ECG time.

Method: Door-to-ECG time was evaluated before and after the insertion of a rapid inflow of the patient with CP to the hospital until the first ECG was performed.

Results: ECG-Gate Time was evaluated in 199 service bulletins, 105 with traditional flow and 94 with a rapid flow of care for DT. Door-toECG Time was 63 minutes using traditional flow, with rapid flow there was a significant reduction of mean door-to-ECG time to 23.31 minutes in all shifts, a general reduction of $63 \%(\mathrm{p}<0.001)$, the daytime period decreased by $61 \%(\mathrm{p}<0.001)$ and the nocturnal period decreased by $63 \%(\mathrm{p}<0.001)$.

Conclusion: A rapid flow to optimize the door-to-ECG time allowed a significant reduction of the time of approach of the patient with CP with only two months of training of the multiprofessional team.

Keywords: Thoracic Pain; Electrocardiography; Myocardial Infarction

\section{Introduction}

Chest Pain (CP) corresponds to one of the most frequent symptoms in the emergency units worldwide and represents a great challenge for all the professionals who work in emergency care services, considering the multiplicity of possible diagnoses and the fluctuation between situations of low and high risk, requiring the emergencista an additional ability to diagnose fast and direct a specific and safe therapy for each case [1-6]. The traditional approach to patients in emergency units in Brazil follows the severity screening approach proposed by the Manchester protocol [7] which, in many cases, may underestimate the severity of the patient with $\mathrm{CP}$, a fact due to the variation in intensity of presentation clinic of severe patients as occurs in acute coronary syndrome. The implementation of a flow directed to CP approach allows to identify and optimize care in severe patients in a fast way, making the approach safer for patients and medical staff.

The insertion of protocols and the training process of the team have a direct repercussion in accelerating arrival times, diagnosis, treatment and therefore in reducing the risks of the patient with CP $[8,9]$. Some indexes guide the measurement of the delay time and, consequently, the efficacy in the evaluation of a patient with $\mathrm{CP}$, among them, door-to-ECG time, a measure that evaluates the time between the patient's arrival at the hospital reception to the filling of the recording protocol until the first electrocardiogram (ECG) was performed [9-12]. The door-to-ECG time considered ideal is 10 minutes, a real agility challenge for the teams of an emergency unit. $[13,14]$ The objective of the study was to implement a protocol 
with a rapid care flow at the entrance of patients with $\mathrm{CP}$ within the emergency unit.

\section{Method}

Place of study - The study was conducted at the Emergency and Cardiology Unit of the University Hospital of Vassouras-RJ, state of Rio de Janeiro, Brazil, approved by the Ethics and Research Committee, under the approval number (1.843.401).Study design - The patient with CP, once identified by the hospital's reception team, did not use the traditional risk screening route according to the Manchester protocol [7], his card received a stamp of Thoracic Pain with the message for rapid care. The nurse responsible for the triage, upon receiving the patient's file at hand, brought by the receptionist, immediately took the patient to the electrocardiogram room. The ECG was then performed by a medical technician or student, who was then delivered immediately to the physician for evaluation of the case, ignoring the natural order of arrival sequence. Purposely, the physician was placed in the last stage of the flow, once belonging to him one of the traditional points of delay resulting from the sequential patient care in order of arrival.

Door-to-ECG time - To measure door-to-ECG time, the hospital electronic cadastre system was used, which provided information about the patient's time of entry into the hospital as well as the time of ECG recording. The times before and after the new flow of care and training of the emergency team were verified.Statistics Initially the normal distribution of the data was verified through the Kolmogorov-Smirnov test. Afterwards, a possible statistical difference was verified through the paired t-test of Student with post-test of Tukey. Data were expressed as mean \pm standard deviation of the mean and a significant $p$ value $<0.05$ was considered.

\section{Results}

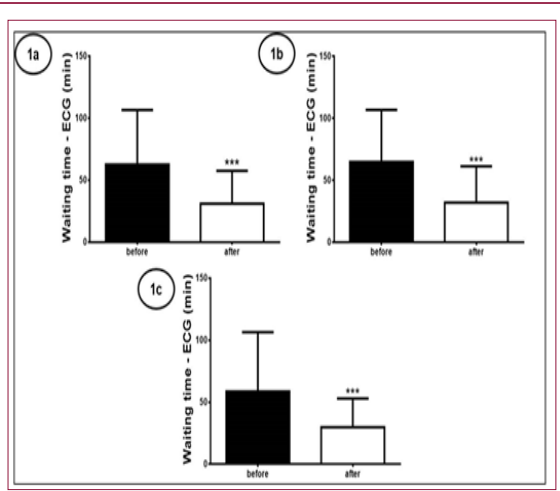

Figure 1: Data Were Expressed as Mean \pm Standard Deviation. The Symbol ***Refers to the Value of $p<0.001$. 1 - 24-hour Shift; 1 b - Day Shift; 1c - Night Shift.

We analyzed 199 medical newsletters of which 105 patients under the traditional flow and 94 under the rapid flow of care.It was verified that the average time between the arrival of the patient with CP in the emergency of the University Hospital of VassourasRJ until being submitted to the ECG was of 63 minutes using the traditional flow, being that in the day period this time was of 65 minutes and in the nocturnal period of 59 minutes, all times above recommended. After the training of the multidisciplinary team, 94 newsletters were checked and a significant reduction in ECG time was observed for 23.31 minutes in all shifts, a general reduction of (Figure 1) 63\% (p <0.001), daytime decreased by 61\% (p <0.001) and the nocturnal period decreased by $63 \%(p<0.001)$.

\section{Discussion}

The door-to-ECG time is responsible for $25 \%$ of delays in the institution of fibrinolytic therapy or primary angioplasty in patients with CP due to acute myocardial infarction $[15,16]$ which is why it is considered an important item of qualification and optimization of the teams within the units of emergency; target to be pursued when seeking the excellence in the service of CP. According to Missagliaet al. [17] the application of the flow protocol in the approach of the $\mathrm{CP}$ in an emergency unit, streamlines and directs the patient care, shortening the time of recognition of the origin of the CP, optimizing the insertion of a suitable therapy, with consequent immediate impact in the mortality of these patients in the first 12 hours of care.

The traditional inflow of the patient with chest pain: reception, risk screening and waiting for medical attention, according to the Manchester protocol, only to perform the ECG, was changed at the University Hospital of Vassouras-RJ for the use of a protocol with a faster inflow, which resulted in a positive impact on the optimization and search for the reduction of door-to-ECG time, with a mean decrease of $63 \%$ in time between hospital admission and the first electrocardiogram (ECG). Phelan MP et al. [18] also observed a decrease in door-to-ECG time in 72 patients with infarction, reduction of 21.3 minutes pre-insertion of rapid protocol to 9.5 minutes in the subsequent phase, 55\% decrease in door-toECG time obtained with the training of a new patient input flow. Another study documented a drop of 10 to 6.3 minutes, a $63 \%$ shortening in door-to-ECG time [19,20]. Therefore, although still far from the ideal goal of 10 minutes according to the protocols of the American College of Cardiology [14], the shortening of the ECG time lag reached in the University Hospital of Vassouras-RJ was the result of the multidisciplinary training of the team in constructing and applying a new path of arrival for the patient with CP, making access, diagnosis and therapy faster, promoting safety and risk minimization to patients and also to the medical team [21-23].

\section{Conclusion}

The insertion of a rapid inflow into the emergency room resulted in a significant reduction in door-to-ECG time, minimizing the initial delay in the diagnosis and, consequently, optimizing a faster therapeutic approach that mainly benefits CP patients with high risk. New flows with fast input must be tested for optimization in patient approach with CP. The characteristics pertinent to each emergency service and the participation of the multidisciplinary team, should be taken into account in the construction of a new flow design.

\section{References}

1. Bassan R, Gibler WB (2001) Chest pain units: state of the art of the management of patients with chest pain in the emergency department. Rev Esp Cardiol Sep 54(9): 1103-1109.

2. Yousuf T, Keshmiri H, Ziffra J, Dave A, Hussain S, et al. (2016) Impact of Chest Pain Protocol Targeting Intermediate Cardiac Risk Patients in an 
Observation Unit of an Academic Tertiary Care Center. J Clin Med Res 8(2): 111-115.

3. Bassan R, Scofano M, Gamarskii R, Dohmann HF, Pimenta L, et al. (2000) A dor torácica na sala de emergência: a importância de uma abordagem sistematizada. Arq Bras Cardiol 74: 13-21.

4. Lee TH, Goldman L (2000) Evaluation of the patient with acute chest pain. N Engl J med (16):1187-1195.

5. Bassan R (2002) Unidades de dor torácica na sala de emergência. Arq Bras Cardiol 79: 196-202.

6. Bahr RD, Copeland C, Strong J (2002) Chest pain centers-Part 1. Chest pain centers: past, present and future. J Cardiovasc Manag 13(2): 19-20.

7. (1997) Emergency Triage: Manchester Triage Group UK 1997. BMJ Publishing.

8. Bahr RD, Copeland C, Strong J (2002) Chest pain centers--Part 3. Evaluation in the hospital ED or chest pain center (CPC). J Cardiovasc Manag 13(2): 23-25.

9. Filippo O, Nicola B, Casagranda I, Cassin M, Cavazza M, et al. (2009) Chest pain evaluation project. G Ital Cardiol (Rome) 10(1): 46-63.

10. Rydman RJ, Zalenski RJ, Roberts RR, Albrecht GA, Misiewicz VM, et al. (1997) Patient satisfaction with an emergency department chest pain observation unit. Ann Emerg Med 29(1): 109-115.

11. Scheuermeyer FX, Christenson J, Innes G, Boychuk B, Yu E, et al. (2010) Safety of assessment ofpatients with potential ischemic chest pain in an emergency department waiting room: a prospective comparative cohort study. Ann Emerg Med 56(5): 455-462.

12. Swap CJ, Nagurney JT (2005) Value and limitations of chest pain history in the evaluation of patients with suspected acute coronary syndromes. JAMA 294(20): 2623-2629.

13. O'Gara PT, Kushner FG, Ascheim DD, Casey DE, Chung MK, et al. (2013) 2013 ACCF/AHA Guideline for the Management of ST-Elevation Myocardial Infarction: Executive Summary. A Report of the American College of Cardiology Foundation/American Heart Association Task Force on Practice Guidelines. Circulation 127(4): 529-555.

14. Angeja BG, Gibson CM, Chin R, Frederick PD, Every NR, et al. (2002) Predictors of door-to-balloon delay in primary angioplasty. Am J Cardiol 89: 1156-1161.

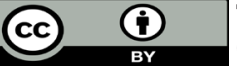

This work is licensed under Creative Commons Attribution 4.0 License

Submission Link: https://biomedres.us/submit-manuscript.php
15. Diercks DB, Peacock WF, Hiestand BC, Chen AY, Pollack CV, et al. (2006) Frequency and consequences of recording an electrocardiogram $>10$ minutes after arrival in na emergency room in non-ST-segment elevation acute coronary syndromes (from the CRUSADE Initiative). Am J Cardiol 97: 437-442.

16. Misaglia TM, Neris ES, Silva MLT (2013) Uso de Protocolo de Dor Torácica em Pronto Atendimento de Hospital Referência em Cardiologia. Rev Bras Cardiol Set 26(5): 374-381.

17. Phelan MP, Glauser J, Smith E, (2009) Improving emergency department doorto- time in ST segment elevation myocardial infarction. Crit Pathw Cardiol 8(3): 119-121.

18. Graff L, Joseph T, Andelman R, Bahr R, DeHart D, et al. (1995) American College of Emergency Physicians information paper: chest pain units in emergency departments - a report from the Short-Term Observation Section. Am J Cardiol 76(14): 1036-1039.

19. Diercks DB, Kirk JD, Lindsell CJ, Pollack CV, Hoekstra JW, et al. (2006) Door-to-ECG time in patients with chest pain presenting to the ED. Am J Emerg Med 24: 1-7.

20. Takakuwa KM, Shofer FS, Hollander JE (2006) The influence of race and gender on time to initial electrocardiogram for patients with chest pain. Acad Emerg Med 13: 867-872.

21. Purim-Shem-Tov YA, Rumoro DP, Veloso J, Zettinger K (2007) Emergency department greeters reduce door-to-ECG time. Crit Pathways Cardiol 6: $165-168$.

22. Berglin Blohm M, Nilsson G, Karlsson T, Herlitz J (1998) The possibility of influencing components of hospital delay time within emergency departments among patients with ST-elevation in the initial electrocardiogram. Eur J Emerg Med 5: 289-296.

23. Caputo RP, Kosinski R, Walford G, Alex Giambartolomei, William Grant, et al. (2005) Effect of continuous quality improvement analysis on the delivery of primary percutaneous revascularization for acute myocardial infarction: a community hospital experience. Catheter Cardiovasc Interv 64: 428-433.

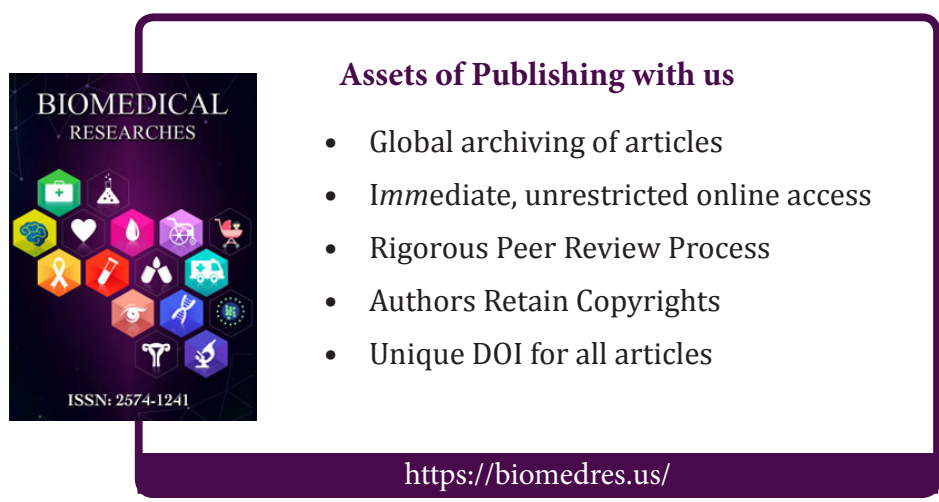

